\title{
Borsa İstanbul'da İşlem Gören Banka Hisse Senetlerinin Volatilite Analizi (Volatility Analysis of Bank Stocks Traded on Bourse Istanbul)
}

\section{Mehmet Sencer GÍRGIN (iD a Tolga ÖZGEN iD b}

a İstanbul Aydın Üniversitesi, İktisadi ve İdari Bilimler Fakültesi, Uluslararası Ticaret ve Finansman Bölümü, girginsencer@yahoo.com

b Aberdeen Üniversitesi, İşletme Fakültesi, Finans Doktora Programı, tolgaozgen@yahoo.com

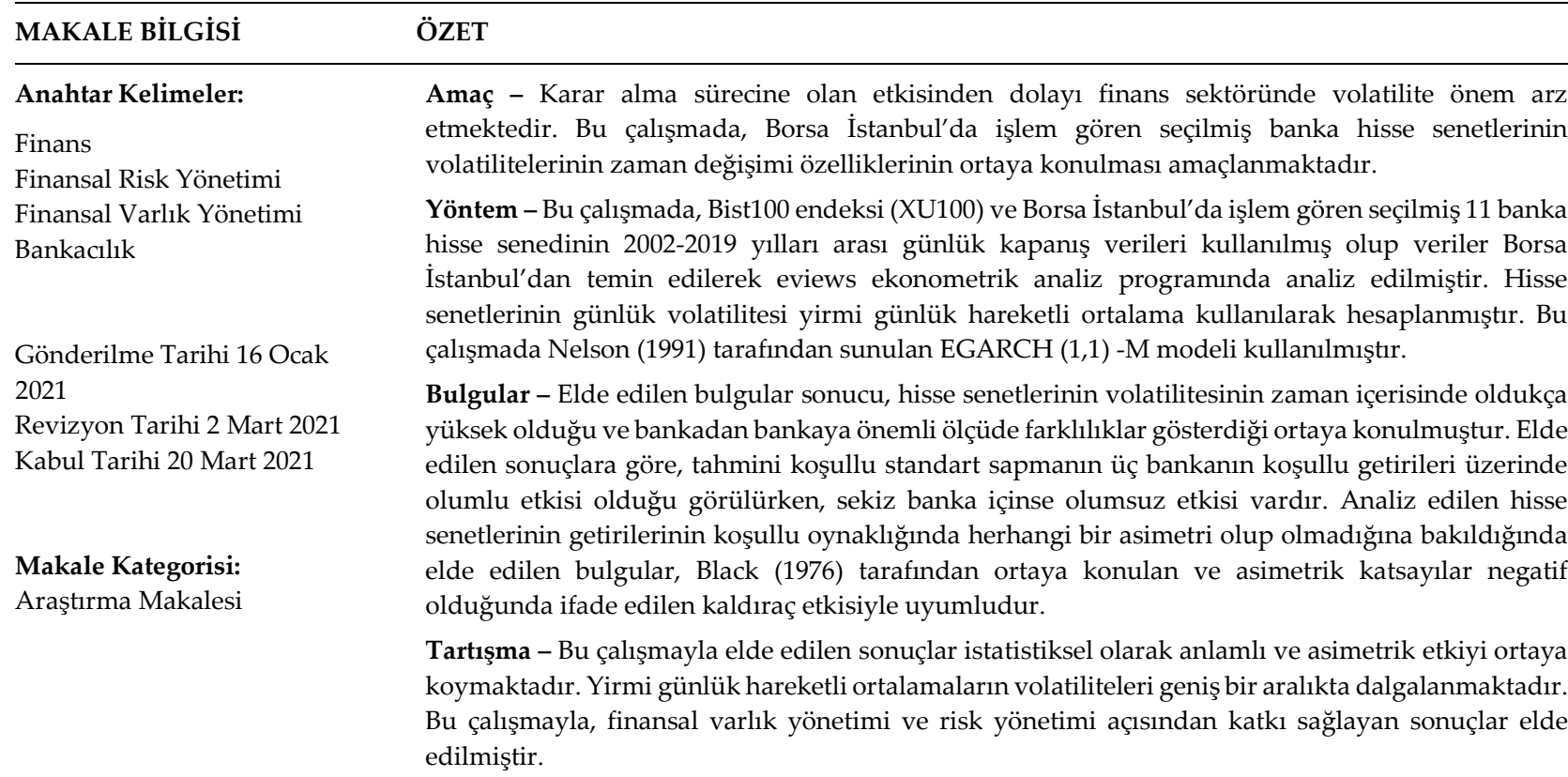

\begin{tabular}{l} 
ARTICLE INFO \\
\hline Keywords: \\
Finance \\
Financial Risk Management \\
Financial Asset Management \\
Banking
\end{tabular}

Received 16 January 2021

Revised 2 March 2021

Accepted 20 March 2021

Article Classification:

Research Article

\section{ABSTRACT}

Purpose - Volatility is important due to its significant impact on decision making in finance sector. This paper aimed to reveal the time-variation characteristics of the volatility of selected bank stocks traded in Borsa Istanbul.

Design/methodology/approach - This paper employs daily data of Bist100 index (XU100) and the stocks of 11 selected banks traded in Borsa Istanbul for the period between 2002-2019. The daily data were obtained from Bourse Istanbul and analyzed in the eviews econometric analysis software. The daily volatility of the selected shares was calculated by using a twenty-day rolling estimation window. In this study, EGARCH (1,1) -M model presented by Nelson (1991) was used.

Findings - Findings provide evidence that the volatility of selected stocks was high across time and showed significant differences from bank to bank. According to the results, the estimated conditional standard deviation has a positive effect on the conditional returns of only 3 banks, however for the remaining 8 banks analyzed, the conditional standard deviation has a negative effect on the conditional mean. The findings obtained when looking at whether there is any asymmetry in the conditional volatility of the individual stock returns are compatible with Black's (1976) leverage effect where the asymmetric coefficients turn out to be negative.

Discussion - The results obtained in this study are statistically significant and reveal the asymmetric effect. The volatility of twenty-day rolling average fluctuates over a wide range. The results contributes to financial asset management and risk management. 


\section{Giriş}

Global dünyanın oluşturduğu şartlar dolayısıyla gelişmiş ve gelişen ülke piyasaları, zamanın gereklerine uyum sağlayarak daha entegre hale gelmiştir. Bu yakınlaşmadan hem gelişmiş hem de gelişen ülke piyasaları çeşitli yararlar sağlamaktadır. Söz konusu entegrasyon sürecinde gelişen piyasalar kendilerini gelişmiş piyasalara adapte ettikçe, sahip oldukları yüksek getiri potansiyeli ve çeşitlendirme olanağı sayesinde daha fazla yerli ve yabancı yatırımcı çekebilmektedir. Diğer yandan gelişen ülkelerde finansal piyasalar, daha büyük ekonomik ve finansal fırsatlar sunmakla beraber daha büyük riskler de içermektedir.

Risk-getiri ilişkisi, finansal yatırım kararı verme sürecine etkilerinden ötürü, finans alanının temel konularından birisi olmuştur. Beklenen getiri, alınan risk düzeyindeki değişikliklere bağlı olarak değişir. Daha yüksek risk daha yüksek beklenen getiriye yol açarken, yatırımcılar daha düşük riskler için daha düşük getiriyi kabul edebilirler. Bunun nedeni, artan riskin daha yüksek beklenen getiri ile ödüllendirilmesidir.

Bu çalışmayla, 2002-2019 yılları arası Borsa İstanbul'da işlem gören banka hisse senetleri volatilitelerinin zaman değişimi özellikleri incelenerek, banka hisse senetlerinin risk analizi amaçlanmaktadır.

Volatilite ve getiri üzerine yapılan araştırmalar incelendiğinde, genel olarak tek bir endeksin ya da şirket hisselerinin baz alındığı, bir çoğunda da farklı ülkelerdeki hisse senedi piyasalarının analiz edildiği görülmektedir.

1994 yılında üç Avrupa borsasında volatilite-hisse senedi getirisi bağlantısını araştıran Corhay ve Rad (1994), kullandıkları GARCH ve AR-GARCH modeliyle riskin varyans tarafından tam anlamiyla ortaya konulabileceğini göstermişlerdir. Avusturalya, Belçika, Kanada, İtalya, Fransa, Japonya, İsviçre, Birleşik Krallık, Amerika Birleşik Devletleri ve Almanya'yı kapsayan araştırmayı yapan Theodossiou ve Lee (1995), bu analizde gelişmiş ülkelerin haftalık borsa verilerini baz almışlardır. Borsanın haftalık getirilerini ve volatilitelerini analiz ederek yaptıkları bu araştırmada, 1976-1991 yılları arasında volatilitenin varlığını ortaya koysalar da, beklenen getiriler ve şartlı volatilite bağlantısına dair bir kanıt olduğu ortaya konulamamıştır.

Xing (2004), otuz yedi uluslararası piyasayı 1973-2000 yılları arasında mercek altına alarak ortaya koyduğu araştırmada, piyasa endeksinin haftalık fiyatlarını analiz etmiş ve ülkeler arasındaki volatilitenin çeşitliliğini araştırmıştır. Yapılan bu araştırmaya göre, yatırımcının eğitim düzeyi arttıkça piyasadaki dalgalanma çok daha azdır. Bununla birlikte Xing'in araştırması ortaya koymuştur ki, borsanın büyüklüğü ve işlem gören şirketlerin sayısı da piyasa volatilitesini önemli ölçüde etkilemektedir.

ARCH, GARCH ve GARCH-M modellerini kullanan Padhi (2006), 1990-2004 yılları arasında Bombay Borsasından seçilen beş endeksi incelemiştir. Padhi bu dönemdeki çeşitli sektörlerden yirmi şirketin Bombay piyasasındaki günlük verilerini baz almıştır. Bu çalışmayla, haberlerin gecikme süresine bağlı olarak volatilitenin değiştiği ortaya konulmuştur.

Yapılan bir diğer önemli araştırma ise 1997 yılında Asya krizini temel alan analizdir. Chancharoenchai ve Dibooğlu (2006), Tayland, Malezya, Kore, Filipinler, Tayvan ve Endonezya'yı inceleyerek, bu ülkelerdeki reel ve finansal sektörlerin krizden nasıl etkilendiğini analiz etmişlerdir. Ayrıca araştırma genişletilerek, bu sayılan ülke piyasalarının üzerindeki ABD ve Japonya etkisi göz önüne alınmış ve bu ülkeler de analize dahil etmiştir. Günlük kapanış fiyatlarını ve GARCH-M metodunu kullanarak, Asya menkul kıymetler piyasalarındaki volatilite yayılmalarını ve ABD ve Japonya ile ilişkilerini incelemişlerdir. Asya krizi ilk olarak Tayland'da başlamakla birlikte bölgedeki ülkelere yayılmasıyla, Asya borsaları arasındaki kuvvetli ilişki ortaya konulmuştur. Bununla birlikte Asya piyasasında yer alan ülkelerin piyasalarındaki risk priminin, dış etkiye karşı oldukça hassas olduğu gözlemlenmiştir.

Söylemez (2020) G20'de yer alan gelişmekte olan ülkelerin bankacılık endeksleri üzerinde MSGARCH modelini uygulayarak yaptığı çalışmada, her ülke bankacılık endeksinin rejimde kalma sürelerinin farklılığını ve rejim değişikliğini ortaya koymuştur.

Volatiliteyi analiz etmek adına Lin ve Chen (1999), Tayvan borsa endeksinin getirilerini baz alarak, ARCH ve GARCH tipi modelleriyle, hisse dalgalanmalarıyla düşük-orta-yüksek volatilite rejimleri arasındaki ilintiyi ortaya koymuşlardır. Bu bağlantıya ek olarak kaldıraç etkisinin varlığına dair deliller bulmuşlardır.

Tahmin edilebilir zamana göre değişken volatilite olduğuna dair kanıtı ise 2001 yılında Balaban, Bayar, Kan (2001) ortaya koymuşlardır. Yapılan analizde, kullanılan ondokuz ülkenin borsa endekslerine bakıldığında üç 


\section{S. Girgin - T. Özen 13/1 (2021) 904-911}

ülkede getiri ve şartlı volatilite arasında anlamlı ilişki bulunmakla birlikte onaltı ülke içinse bağlantı bulunamamıştır. Fakat ülkeler arasındaki getiri ve koşullu volatilite ilişkisi birbirinden farklıdır. Örneğin, sekiz ülke volatilitesinde mevsimsellik etkisi göstermekteyken, diğer yedi ülke ortalama getirilerinde mevsimsellik etkisi göstermektedir. Ayrıca Balaban (2002) on ülkenin şartlı volatiliteleri üzerinde kaldıraç etkisini ve volatilitenin zamana bağlı değişkenlik gösterdiğini kanıtlamıştır.

Yapılan diğer bir araştırmada, Brezilya borsasını baz alan, hisse senedi getirileri, işlem hacmi ve hisse senedi volatilitesi arasındaki bağlantıyı ortaya koyan bir analizdir. Medeiros ve Doornik (2006) tarafından yapılan çapraz korelasyon analizi, birim kök testleri, iki değişkenli eş zamanlı denklem regresyonu, VAR modellemesi, Granger testi ve GARCH modellemesi gibi yöntemler kullanılarak, hisse senedi getirileri, işlem hacimleri ve volatilite-işlem hacimleri arasındaki ilişki ortaya konulmuştur. Yapılan analiz, ARCH etkisinin varlığını GARCH $(1,1)$ testleriyle ortaya koymuştur.

Mohamad ve Mahmood (2001), GARCH $(1,1)$ modellerini kullanarak Kuala Lumpur borsa endeksinin ve döviz kurunun değişkenliğini incelemişlerdir. 1997-1999 tarihleri arasındaki endeks verileri bu araştırmaya temel oluşturmuştur. Araştırmanın bu kadar küçük bir ülkenin borsasını incelemesinin sebebi ise Asya krizi sırasındaki volatiliyeyi küçük pazarlar açısında incelemektir. Sonuçlar ise hisse senedi endeksi ve döviz kuru oynaklığı tahmini arasındaki anlamlı ilişkiyi göstermektedir. Eğer borsa endeksinde bir artış varsa döviz kurundaki değişkenlik artmaktadır.

Şirket finansal bilgilerinin açıklanmasıyla borsa volatilitesi arasındaki ilişki ise Medeiros ve Quinteiro (2005) tarafından yapılan araştırmada ortaya konulmuştur. Bu çalışmada, şirket finansal bilgilerinin kalitesi arttıkça, işlem gören hisselerin daha az dalgalı olduğu tezini denemek amacıyla Brezilya borsasına kote edilen 40 şirket incelenmiştir. Sonuç olarak önceki çalışmalarla uyumlu tezlerini desteklemişlerdir.

Pozitif getirilerin etkisinin, negatif getirilere oranla daha düşük olduğunu ispatlayan bir araştırma da Wong ve Yang (2018) tarafından ortaya konulmuştur. S\&P 500 ETF ve S\&P 100 endeksleri üzerinde yaptıkları analizde, volatilite ile getiri arasındaki bağlam ortaya konulmuştur.

Diğer yandan, volatilitenin kalıcılığı ve asimetri etkisini Chen ve Wang (2019) araştırmışlardır. Yaptıkları araştırmaya temel olarak gelişmiş ve gelişmekte olan yirmi üç ülkeyi almışlardır. Bu ülkelerden topladıkları yirmi sekiz endekse ait verileri analiz etmişlerdir. Sonuç olarak, volatilitenin kalıcılığı ile getiriler arasındaki bağ 1 temellendirerek, pozitif getiri etkisinin bu düzlemde negatif getirilere nazaran daha az olduğunu ispatlamışlardır.

Bayçelebi ve Ertuğrul (2020) BIST bankacılık endeksinin günlük kapanış verilerini kullanarak 2010-2016 yılları arasındaki volatilitesini GARCH, TGARCH ve EGARCH modelleri ile analiz etmişlerdir. Uygulanan modellerden $\mathrm{GARCH}(1,1)^{\prime}$ in analiz edilen dönemdeki volatiliteyi diğer modellere göre daha iyi açıkladığ 1 ortaya konulmuştur.

Kula ve Baykurt (2020) BIST bankacılık endeksinin 1997-2016 yılları arasındaki volatilitesini MSGARCH modeli kullanarak analiz etmişlerdir. Elde edilen sonuçlar bankacılık endeksinde düşük volatilite israrcılığı olduğu, yüksek risk rejim volatilitesinin düşük rejime göre çok daha yüksek olduğu ortaya konulmuştur.

Söylemez (2019) BIST bankacılık endeks volatilitesini 1997-2019 yılları arası endeks kapanış verilerini kullanarak incelemiştir. Farklı GARCH modelleri kullanılarak yapılan bu analiz sonuçlarına göre CGARCH modelinin bankacılık endeksi analizine diğer GARCH modellerinden daha uygun olduğu sonucuna varılmıştır. Aynı zamanda elde edilen sonuçlarla volatilite ısrarcılığı ortaya konulmuştur.

BIST-100'de firma düzeyinde volatiliteye odaklanan sınırlı çalışmalardan biri olan Balaban ve Özgen (2016), firma bazında günlük işlem verilerini analiz ederek işlem seansı etkilerini araştırmışlardır.

Türkiye borsası için bankalar düzeyinde yapılan bu çalışmayla inceleme konusuna yönelik literatüre anlamlı bir katkı ortaya konulması amaçlanmaktadır.

\section{Yöntem}


Bu çalışmada, Ocak 2002 - Şubat 2019 yılları arası döneme ait Bist100 endeksi (XU100) ve seçilmiş 11 banka hisse senedinin günlük kapanış verileri kullanılmış olup veriler Borsa İstanbul'dan temin edilerek eviews programında analiz edilmiştir. Seçilen örneklem dönemi, 2001 krizinden sonrasını kapsamaktadır.

Günlük getiriler, aşağıda gösterilen formül kullanılarak hesaplanmaktadır:

$$
\text { getiri }=100 \times \ln \frac{P_{t}}{P_{t-1}}
$$

Bu çalışmada, Nelson (1991) tarafından sunulan EGARCH (1,1) -M modeli kullanılmaktadır.

$$
R_{t}=\beta \ln \left(\sigma_{t}^{2}\right)+c+\sum_{i=1}^{p} \delta_{i} R_{t-1}+\mu_{t}
$$

Yukarıda verilen getiri fonksiyonu göz önüne alındığında, EGARCH $(1,1)$-M modeli aşağıdaki gibi ifade edilebilir:

$$
\ln \left(\sigma_{\mathrm{t}}^{2}\right)=\omega+\alpha\left[\frac{\left|\mu_{t-1}\right|}{\sqrt{\sigma_{t-1}^{2}}}-\sqrt{\frac{2}{\pi}}\right]+\gamma \frac{\mu_{t-1}}{\sqrt{\sigma_{t-1}^{2}}}+\beta \ln \left(\sigma_{t-1}^{2}\right)
$$

$R_{t}$ her bir hisse senedinin getirisi ve piyasa endeksi getirisi anlamına gelmektedir. Modelde tahmini koşullu standart sapma $\ln \left(\sigma_{\mathrm{t}}^{2}\right)$ getiri fonksiyonuna girmektedir. Denklemdeki $c$ katsayısı basit ifadeyle sabit terimdir. Otoregresif etkiler varsa, bu etkiler $\delta_{\mathrm{i}}$ katsayısı/katsayıları ile ölçülür. $\mu_{t}$ modelin hata terimidir. Koşullu varyans $\ln \left(\sigma_{\mathrm{t}}^{2}\right)$ ile ifade edilmektedir. Kullanılan asimetrik model, pozitif ve negatif hataların koşullu varyans üzerindeki etkilerini ayırt edebilmektedir. Negatif hataların etkisi, koşullu varyans fonksiyonundaki $\gamma$ katsayısı ile ifade edilmektedir. Eğer $\gamma$ önemli ölçüde negatifse, bu durumda kaldıraç etkisinden söz edilebilir (Black, 1976; Glosten, Jaganathan ve Runkle, 1993).

EGARCH modellerinde koşullu varyans özelliklerine bakılacak olursa, tahmini koşullu oynaklığın durağan ve negatif olmadığı gözlemlenmektedir. Koşullu oynaklık belirtimindeki $\beta$ katsayısı, önceki dönemin tahmini koşullu oynaklığını ifade eder ve genellikle oynaklığın sürekliliğinin/kalıcılı̆̆ının bir ölçüsü olarak görülür.

\section{Bulgular}

Bu çalışmada, Borsa İstanbul'da işlem gören seçilmiş bankaların günlük volatilitesindeki zaman değişiminin özellikleri incelenmiştir. Elde edilen ampirik bulgular, günlük volatilitenin zaman içerisinde yüksek olduğunu ve bankalar arasında önemli ölçüde farklılıklar gösterdiğini ortaya koymaktadır.

Tablo 1. Hisse Getirilerinin İstatistik Özetleri 
M. S. Girgin - T. Özen 13/1 (2021) 904-911

\begin{tabular}{|c|c|c|c|c|c|c|}
\hline & & \multicolumn{3}{|c|}{ ALBARAKA } & \multirow{2}{*}{$\begin{array}{l}\text { GARANTI } \\
\text { BANKASI } \\
\end{array}$} & \multirow{2}{*}{$\begin{array}{c}\text { T. HALK } \\
\text { BANKASI } \\
\end{array}$} \\
\hline & XU100 & AKBANK & TURK & DENIZBANK & & \\
\hline Ortalama & 0.05 & 0.01 & -0.03 & 0.05 & 0.03 & -0.01 \\
\hline Standart Sapma & 1.79 & 2.69 & 2.03 & 3.03 & 3.22 & 3.34 \\
\hline Minimum & -13.34 & -19.94 & -11.23 & -16.19 & -17.38 & -15.34 \\
\hline Alt $1 \%$ & -4.86 & -6.87 & -6.09 & -8.30 & -9.53 & -9.69 \\
\hline Alt 5\% & -2.84 & -4.13 & -3.17 & -4.14 & -4.91 & -5.49 \\
\hline Alt $10 \%$ & -1.98 & -3.03 & -2.27 & -2.68 & -3.51 & -3.78 \\
\hline Alt $25 \%$ & -0.90 & -1.49 & -0.98 & -1.09 & -1.67 & -1.68 \\
\hline Üst 25\% & 1.04 & 1.49 & 0.92 & 0.90 & 1.80 & 1.76 \\
\hline Üst 90\% & 2.01 & 3.07 & 2.23 & 2.66 & 3.64 & 3.70 \\
\hline Üst 95\% & 2.76 & 4.34 & 3.08 & 4.57 & 4.74 & 5.09 \\
\hline Üst 99\% & 4.51 & 6.96 & 5.79 & 11.19 & 8.14 & 9.31 \\
\hline Maksimum & 12.13 & 18.95 & 11.53 & 19.29 & 18.73 & 14.99 \\
\hline Değ işim Aralığ 1 & 25.47 & 38.89 & 22.76 & 35.49 & 36.12 & 30.33 \\
\hline \multirow[t]{2}{*}{ Değ işim Aralığ / Volatilite } & 14.19 & 14.45 & 11.21 & 11.72 & 11.20 & 9.07 \\
\hline & IS BANKASI (C) & $\begin{array}{c}\text { QNB } \\
\text { FINANSBANK } \\
\end{array}$ & SEKERBANK & T.S.K.B. & $\begin{array}{c}\text { VAKIFLAR } \\
\text { BANKASI } \\
\end{array}$ & $\begin{array}{c}\text { YAPI VE KREDI } \\
\text { BANKASI } \\
\end{array}$ \\
\hline Ortalama & -0.01 & 0.04 & 0.01 & 0.00 & 0.00 & -0.02 \\
\hline Standart Sapma & 3.14 & 3.37 & 3.00 & 3.26 & 3.18 & 3.24 \\
\hline Minimum & -19.69 & -17.99 & -15.82 & -20.39 & -15.38 & -15.81 \\
\hline Alt $1 \%$ & -8.65 & -9.83 & -8.59 & -10.36 & -9.12 & -9.68 \\
\hline Alt 5\% & -4.96 & -4.85 & -4.47 & -5.00 & -5.08 & -5.19 \\
\hline Alt $10 \%$ & -3.42 & -3.13 & -3.05 & -3.28 & -3.64 & -3.59 \\
\hline Alt $25 \%$ & -1.61 & -1.24 & -1.31 & -1.50 & -1.71 & -1.60 \\
\hline Üst $25 \%$ & 1.64 & 1.06 & 1.22 & 1.54 & 1.69 & 1.68 \\
\hline Üst 90\% & 3.29 & 3.33 & 3.05 & 3.52 & 3.50 & 3.46 \\
\hline Üst 95\% & 4.68 & 5.47 & 4.55 & 4.91 & 4.74 & 4.78 \\
\hline Üst 99\% & 8.39 & 11.54 & 9.66 & 9.21 & 8.70 & 9.38 \\
\hline Maksimum & 19.55 & 18.23 & 18.61 & 17.61 & 16.50 & 16.99 \\
\hline Değişim Aralığ1 & 39.24 & 36.22 & 34.43 & 38.00 & 31.88 & 32.80 \\
\hline Değişim Aralığ / Volatilite & 12.48 & 10.75 & 11.50 & 11.65 & 10.04 & 10.13 \\
\hline
\end{tabular}

Tablo 1'de gösterilen hisse getirilerinin istatistik özet sonuçları dikkate alındığında, günlük getiriler -0.03 (AlbarakaTürk) ile 0.05 (Denizbank) arasında değişmektedir. Minimum değerler dikkate alındığında, XU100 hariç, -20.3 (TSKB) ile -11.2 (AlbarakaTürk) aralığındadır. Maksimum değerler ise 11.5 (AlbarakaTürk) ile 19.5 (İşbankası C) aralığında değişkenlik göstermektedir.

Sonuçlar dikkate alındığında, Qnb Finansbank 3.37 ile en yüksek standart sapmaya sahipken, AlbarakaTürk 2.03 ile en düşük standart sapmaya sahiptir. Analiz edilen sürede BIST100 endeksinin volatilitesi 1.79 'dur. Alt \%25 dördün hariç tutulduğunda, getiri değişim aralığ -1.71 ile 1.80 olarak değişmektedir. Üst \%25 hariç tutulduğunda ise, minimum getiri 0.90 olarak değişirken, maksimum volatilite 1.80 olmaktadır. 
M. S. Girgin - T. Özen 13/1 (2021) 904-911

Tablo 2. EGARCH $(1,1)$-M Modeli Ampirik Sonuçlar

\begin{tabular}{|c|c|c|c|c|c|c|c|c|c|c|c|c|}
\hline & \multicolumn{3}{|c|}{$\begin{array}{c}\text { XU100 } \\
\text { Ortalama Denklemi }\end{array}$} & \multicolumn{3}{|c|}{$\begin{array}{c}\text { AKBANK } \\
\text { Ortalama Denklemi }\end{array}$} & \multicolumn{3}{|c|}{$\begin{array}{l}\text { ALBARAKA TÜRK } \\
\text { Ortalama Denklemi }\end{array}$} & \multicolumn{3}{|c|}{$\begin{array}{c}\text { DENiZBANK } \\
\text { Ortalama Denklemi }\end{array}$} \\
\hline & Katsayı & & z-İstatistiğ $\mathrm{i}$ & Katsay 1 & & $z$-İstatistiği & Katsay 1 & & $z$-İstatis tiği & Katsayı & & $z$-İstatistiğ $\mathrm{i}$ \\
\hline$\beta$ & $-0,0502$ & & $-1,2032$ & 0,0178 & & 0,2267 & 0,0522 & & 0,6826 & $-0,0358$ & & $-0,7081$ \\
\hline $\mathrm{C}$ & 0,1015 & $* * *$ & 2,8577 & $-0,0097$ & & $-0,0733$ & $-0,0831$ & & $-0,9467$ & 0,0637 & & 0,8682 \\
\hline$\theta_{1}$ & 0,0259 & & 1,6197 & 0,0084 & & 0,5404 & 0,0017 & & 0,0807 & 0,0106 & & 0,5605 \\
\hline$\theta_{2}$ & 0,0120 & & 0,7809 & $-0,0211$ & & $-1,4274$ & 0,0208 & & 1,0414 & $-0,0407$ & $* * *$ & $-2,4185$ \\
\hline$\theta_{3}$ & $-0,0025$ & & $-0,1656$ & $-0,0018$ & & $-0,1122$ & 0,0577 & $* * *$ & 3,0522 & $-0,0329$ & $* *$ & $-2,0875$ \\
\hline$\theta_{4}$ & 0,0023 & & 0,1464 & $-0,0135$ & & $-0,8282$ & 0,0208 & & 1,0869 & $-0,0138$ & & $-0,8565$ \\
\hline \multirow[t]{3}{*}{$\theta_{5}$} & $-0,0026$ & & $-0,1664$ & $-0,0294$ & $*$ & $-1,8825$ & $-0,0020$ & & $-0,1008$ & 0,0110 & & 0,7177 \\
\hline & \multicolumn{3}{|c|}{ Varyans Denklemi } & \multicolumn{3}{|c|}{ Varyans Denklemi } & \multicolumn{3}{|c|}{ Varyans Denklemi } & \multicolumn{3}{|c|}{ Varyans Denklemi } \\
\hline & Katsayı & & z-İs tatistiğ $\mathrm{i}$ & Katsay 1 & & z-İstatistiği & Katsay 1 & & $z$-İstatis tiği & Katsay 1 & & z-İs tatis tiğ $\mathrm{i}$ \\
\hline $\mathrm{W}$ & $-0,1139$ & $* * *$ & $-15,1037$ & $-0,0607$ & $* * *$ & $-8,8177$ & $-0,0757$ & $* * *$ & $-5,3699$ & $-0,0622$ & $* * *$ & $-5,9060$ \\
\hline$\alpha$ & 0,1821 & $* * *$ & 18,3272 & 0,1431 & $* * *$ & 16,4579 & 0,3072 & $* * *$ & 16,1078 & 0,4500 & $* * *$ & 32,1923 \\
\hline$\gamma$ & $-0,0520$ & $* * *$ & $-9,5611$ & $-0,0326$ & $* * *$ & $-5,8369$ & $-0,0235$ & $* *$ & $-2,1577$ & $-0,0170$ & $*$ & $-1,7893$ \\
\hline \multirow[t]{3}{*}{$\beta$} & 0,9740 & $* * *$ & 330,7676 & 0,9750 & $* * *$ & 343,9666 & 0,8830 & $* * *$ & 78,0227 & 0,8793 & $* * *$ & 196,4862 \\
\hline & $\begin{array}{r}\text { GARAN } \\
\text { Ortalar }\end{array}$ & Ortalama Denklemi & $\begin{array}{l}\text { ANKASI } \\
\text { nklemi }\end{array}$ & $\begin{array}{r}\text { iş } \mathbf{B} \\
\text { Ortala }\end{array}$ & $\begin{array}{l}\text { NKA } \\
\text { De }\end{array}$ & $\begin{array}{l}\text { ASI C } \\
\text { nklemi }\end{array}$ & $\begin{array}{r}\text { QNB F } \\
\text { Ortalat }\end{array}$ & $\begin{array}{l}\text { NAN } \\
\text { a De }\end{array}$ & $\begin{array}{l}\text { SBANK } \\
\text { nklemi }\end{array}$ & $\begin{array}{r}\text { ŞEK } \\
\text { Ortalar }\end{array}$ & Ortalama Denklemi & $\begin{array}{l}\text { ANK } \\
\text { nklemi }\end{array}$ \\
\hline & Katsayı & & $\mathrm{z}$-İstatistiğ $\mathrm{i}$ & Katsay 1 & & z-İstatistiği & Katsay 1 & & $z$-İstatistiğ $\mathrm{i}$ & Katsay 1 & & z-İstatistiğ $\mathrm{i}$ \\
\hline$\beta$ & $-0,1113$ & & $-1,3298$ & $-0,1518$ & $* *$ & $-2,0073$ & $-0,0448$ & & $-0,8677$ & 0,0214 & & 0,3278 \\
\hline $\mathrm{C}$ & 0,2968 & $*$ & 1,7825 & 0,2949 & $* *$ & 2,0893 & 0,0755 & & 0,8385 & $-0,0229$ & & $-0,2156$ \\
\hline$\theta_{1}$ & $-0,0780$ & $* * *$ & $-5,1395$ & $-0,0723$ & $* * *$ & $-4,7386$ & $-0,0875$ & $* *$ & $-5,4451$ & 0,0388 & $* * *$ & 2,4448 \\
\hline$\theta_{2}$ & 0,0017 & & 0,1111 & 0,0073 & & 0,4787 & $-0,0123$ & & $-0,7665$ & 0,0184 & & 1,1753 \\
\hline$\theta_{3}$ & $-0,0235$ & & $-1,4878$ & 0,0141 & & 0,9076 & $-0,0354$ & $* * *$ & $-2,3769$ & 0,0132 & & 0,8366 \\
\hline$\theta_{4}$ & $-0,0318$ & $* *$ & $-2,0135$ & $-0,0117$ & & $-0,7565$ & $-0,0115$ & & $-0,8361$ & 0,0077 & & 0,5493 \\
\hline \multirow[t]{3}{*}{$\theta_{5}$} & $-0,0078$ & & $-0,5026$ & 0,0057 & & 0,3871 & 0,0116 & & 0,8111 & 0,0096 & & 0,6380 \\
\hline & \multicolumn{3}{|c|}{ Varyans Denklemi } & Varya & $s$ Der & nklemi & Varya & $s$ Del & nklemi & Varyar & s Den & nklemi \\
\hline & Katsay 1 & & z-İstatis tiği & Katsay 1 & & z-İstatistiği & Katsay 1 & & z-İstatis tiği & Katsay 1 & & $\mathrm{z}$-İs tatis tiğ $\mathrm{i}$ \\
\hline W & $-0,0724$ & $* * *$ & $-8,6721$ & $-0,0956$ & $* * *$ & $-9,9670$ & $-0,0277$ & $* * *$ & $-5,6053$ & $-0,0726$ & $* * *$ & $-9,0570$ \\
\hline$\alpha$ & 0,1797 & $* * *$ & 22,0679 & 0,2166 & $* * *$ & 17,6282 & 0,2795 & $* * *$ & 32,7100 & 0,3246 & $* * *$ & 30,2524 \\
\hline$\gamma$ & $-0,0152$ & $* * *$ & $-2,5649$ & $-0,0095$ & & $-1,4145$ & 0,0314 & $* * *$ & 4,9716 & 0,0173 & $* *$ & 2,2138 \\
\hline$\beta$ & 0,9712 & $* * *$ & 266,6160 & 0,9673 & $* * *$ & 279,1863 & 0,9274 & $* * *$ & 308,4845 & 0,9181 & $* * *$ & 215,4683 \\
\hline & $\begin{array}{r}\text { HALK } \\
\text { Ortalar }\end{array}$ & $\begin{array}{l}\text { BAI } \\
\text { a De }\end{array}$ & $\begin{array}{l}\text { NKASI } \\
\text { nklemi }\end{array}$ & Ortala & SKB & nklemi & $\begin{array}{r}\text { VAKIFL } \\
\text { Ortalaı }\end{array}$ & $\begin{array}{l}\mathbf{A R} \mathbf{B} \\
\text { a De }\end{array}$ & $\begin{array}{l}\text { ANKASI } \\
\text { nklemi }\end{array}$ & $\begin{array}{r}\text { YAPI } \\
\text { Ortalar }\end{array}$ & $\begin{array}{l}\text { VE K } \\
\text { a Del }\end{array}$ & $\begin{array}{l}\text { REDİ } \\
\text { nklemi }\end{array}$ \\
\hline & Katsay 1 & & $\mathrm{z}$-İstatistiğ $\mathrm{i}$ & Katsayı & & z-İstatistiğ $\mathrm{i}$ & Katsay 1 & & z-İstatistiğ $\mathrm{i}$ & Katsay 1 & & $\mathrm{z}$-İstatistiğ $\mathrm{i}$ \\
\hline$\beta$ & $-0,0624$ & & $-0,6689$ & $-0,1578$ & $* *$ & $-2,1198$ & $-0,0636$ & & $-0,6789$ & $-0,1994$ & $* * *$ & $-2,9228$ \\
\hline $\mathrm{C}$ & 0,1559 & & 0,8547 & 0,3389 & $* * *$ & 2,3568 & 0,1536 & & 0,8445 & 0,4180 & $* * *$ & 3,3630 \\
\hline$\theta_{1}$ & $-0,0689$ & $* * *$ & $-3,8993$ & $-0,0395$ & $* * *$ & $-2,4263$ & $-0,0384$ & $* *$ & $-2,1416$ & $-0,0557$ & $* * *$ & $-3,6005$ \\
\hline$\theta_{2}$ & $-0,0114$ & & $-0,5949$ & $-0,0056$ & & $-0,3366$ & 0,0028 & & 0,1546 & $-0,0008$ & & $-0,0477$ \\
\hline$\theta_{3}$ & 0,0051 & & 0,2575 & $-0,0215$ & & $-1,3202$ & 0,0185 & & 1,0506 & 0,0130 & & 0,8123 \\
\hline$\theta_{4}$ & $-0,0300$ & & $-1,6032$ & 0,0348 & $* *$ & 2,1916 & 0,0153 & & 0,8676 & $-0,0062$ & & $-0,4008$ \\
\hline$\theta_{5}$ & 0,0235 & & 1,2741 & $-0,0378$ & $* * *$ & $-2,4109$ & $-0,0021$ & & $-0,1172$ & 0,0171 & & 1,0896 \\
\hline & Varyar & s Del & nklemi & Varya & s Der & nklemi & Varya & s Del & nklemi & Varyaı & s Den & nklemi \\
\hline & Katsayı & & $z$-İstatistiği & Katsay 1 & & $z$-İstatistiğ $\mathrm{i}$ & Katsay 1 & & $z$-İstatistiğ $\mathrm{i}$ & Katsayı & & $z$-İstatistiğ $\mathrm{i}$ \\
\hline W & $-0,0858$ & $* * *$ & $-8,0359$ & $-0,0755$ & $* * *$ & $-9,9382$ & $-0,0826$ & $* * *$ & $-6,5714$ & $-0,1151$ & $* * *$ & $-10,8324$ \\
\hline$\alpha$ & 0,1866 & $* * *$ & 12,2215 & 0,2708 & $* * *$ & 21,4561 & 0,2147 & $* * *$ & 15,2134 & 0,2381 & $* * *$ & 21,8975 \\
\hline$\gamma$ & $-0,0185$ & $* *$ & $-2,0137$ & $-0,0318$ & $* * *$ & $-3,9286$ & $-0,0426$ & $* * *$ & $-4,4062$ & $-0,0213$ & $* * *$ & $-2,7517$ \\
\hline$\beta$ & 0,9747 & $* * *$ & 227,1221 & 0,9448 & $* * *$ & 240,4979 & 0,9618 & $* * *$ & 175,1430 & 0,9693 & $* * *$ & 284,2981 \\
\hline
\end{tabular}

${ }^{*} 10 \%$ anlamlılı seviyesini, ${ }^{* *} 5 \%$ anlamlılık seviyesini, ${ }^{* * *} 1 \%$ anlamlılık seviyesini temsil etmektedir.

Tablo 2'de ortaya konulan sonuçlara göre, tahmini koşullu standart sapmanın sadece Akbank, Albarakatürk ve Şekerbank olmak üzere 3 bankanın koşullu getirileri üzerinde olumlu etkisi olduğu görülmektedir. Ancak, bu sonuçların hiçbiri anlamlı değildir. Analiz edilen diğer 8 banka içinse, koşullu standart sapmanın koşullu ortalama üzerinde olumsuz bir etkisi vardır. Bunlardan sadece İşbank-C, TSKB, Yapı ve Kredi Bankası 


\section{S. Girgin - T. Özen 13/1 (2021) 904-911}

anlamlılık göstermektedir. İşBank-C ve TSKB \%5 düzeyinde anlamlılık gösterirken, Yapı ve Kredi Bankası \%1 düzeyinde anlamlılık göstermektedir.

Tablo 2 ayrıca, 11 bankanın münferit hisse senedi getirilerinin koşullu oynaklığında herhangi bir asimetri olup olmadığına dair özet sonuçları göstermektedir. Elde edilen genel bulgular, Black (1976) tarafından ortaya konulan ve asimetrik katsayılar negatif olduğunda ifade edilen, kaldıraç etkisiyle uyumludur.

Black, firmanın değerindeki bir düşüşün, hisse senetlerinde negatif getiriye neden olacağını ve bu durumun genellikle hissenin kaldıraç oranını artıracağını savunmuştur. Black'e göre, finans literatüründe asimetrik oynaklık kaldıraç etkisi ile açıklanabilir ve borç-öz sermaye oranındaki bu artış kesinlikle hisse senedinin oynaklığı anlamına gelmektedir (Black, 1976). Başka bir deyişle, hisse senedi piyasalarında negatif şok, koşullu oynaklığı, aynı büyüklükteki pozitif şoktan daha fazla arttırır. Piyasada olumsuz şoklar (haberler) meydana geldiğinde oynaklık artar.

$\mathrm{Bu}$ çalışmada elde edilen sonuçlar istatistiksel olarak anlamlı ve bu nedenle asimetrik etkiyi ortaya koymaktadır. Koşullu oynaklık fonksiyonundaki asimetrik katsayının, iki banka için pozitif, yedi banka için negatif olduğu bulunmuştur. Ancak, negatif katsayılardan İş Bankası- $C$ dışında hepsi en az \%10 düzeyinde anlamlı iken, QNB Finansbank ve Şekerbank sirasıyla \%1 ve \%5 düzeyinde anlamlı negatif katsayılar sunmaktadır.

Kullanılan model, \%10'luk düzenleyici dönemsel fiyat limiti ve küçük veya likit olmayan şirketlerde telaffuz edilen olası zayıf işlem hacmi gibi pazar mikroyapı etkileri ile açıklanabilen beş gecikmeye (lag) kadar otoregresif terimleri içerir. Katsayıları negatif ve istatistiksel olarak \%1 düzeyinde anlamlı olan Garanti Bankası, İşbank-C, Halkbank, TSKB, Yapı ve Kredi lag-1 de birinci derece otokorelasyon gösterirken, QNB Finansbank ve Vakıfbank ise \%5 düzeyinde istatistiksel olarak anlamlılık göstermektedir. Sadece Şekerbank \%1 anlamlılık düzeyinde pozitif katsayı sunmaktadır. Denizbank, lag-2'de birinci derece otokorelasyon için \%1 anlamlılık düzeyinde negatif katsayı gösterirken, AlbarakaTürk, lag-3'te pozitif birinci derece otokorelasyon sunmaktadır. Sadece Akbank, lag-5'te \%10 anlamlılık düzeyinde negatif katsayı sunmaktadır.

Bu çalışmada, Borsa İstanbul'da işlem gören seçilmiş bankaların günlük volatilitesindeki zaman değişiminin özellikleri incelenmiştir. Elde edilen ampirik bulgular, günlük volatilitenin zaman içerisinde oldukça yüksek olduğunu ve bankalar arasında önemli ölçüde farklılıklar gösterdiğini ortaya koymaktadır.

\section{Sonuç ve Tartışma}

Hisse senetleri Borsa İstanbul'da işlem gören, seçilmiş banka hisse senetlerinin günlük volatilitesindeki zaman değişimi özelliklerinin analiz edildiği bu çalışmada, 2002-2019 dönemi için seçilen 11 banka hisse senedine ait günlük veriler kullanılmıştır. Günlük volatilite, yirmi günlük hareketli ortalama kullanılarak hesaplanmıştır. Buna göre elde edilen ampirik bulgular sonucunda, günlük volatilitenin zaman içerisinde oldukça değişken olduğu ve bankalar arasında önemli ölçüde farklılıklar gösterdiği ortaya konulmuştur.

Ayrıca elde edilen bulgulara bakıldığında, tahmini koşullu standart sapmanın üç bankanın koşullu getirileri üzerinde olumlu etkisi olduğu görülürken, sekiz banka için ise olumsuz etkisi olduğu gözlemlenmektedir.

Analiz edilen banka hisse senetlerinin getirilerinin koşullu oynaklığında herhangi bir asimetri olup olmadığına bakıldığında elde edilen sonuçlar Black (1976) tarafından ortaya konulan ve asimetrik katsayılar negatif olduğunda ifade edilen kaldıraç etkisiyle uyumludur. Bu çalışmada elde edilen sonuçlar istatistiksel olarak anlamlı ve asimetrik etkiyi ortaya koymaktadır.

Borsa İstanbul için bankalar düzeyinde volatiliteye odaklanan bu çalışmayla, inceleme konusuna yönelik özellikle finansal varlık yönetimi ve risk yönetimi açısından anlamlı bir katkı ortaya konulmuştur.

\section{Kaynakça}

Balaban, E., (2002), Forecasting Stock Market Volatility: Evidence From Fourteen Countries, Working Paper, Center For Financial Markets Research, University of Edinburgh. 
Balaban, E., Bayar, A. and Kan, B., (2001), Stock Returns, Seasonality and Asymmetric Conditional Volatility In World Equity Markets, Applied Economics Letters, 8, 263-268.

Balaban, E. and Ozgen, T., (2016), Trading Session Effects On Stock Returns and Their Conditional Volatility: Firm-level Evidence From a European Union Accession Country, Physica A: Statistical Mechanics and Its Applications, 446, 264-271.

Bayçelebi, B., Ertuğrul, M. (2020), BIST Banka Endeksi Volatilitesinin GARCH Modelleri Kullanılarak Modellenmesi, Anadolu Üniversitesi Sosyal Bilimler Dergisi, 20(1), 233-244. DOI: 10.18037/ausbd.700351

Black, F. (1976) Studies In Stock Price Volatility Changes, Proceedings of the 1976 Meeting of the Business and Economic Statistics Section, American Statistical Association, 177-181.

Chancharoenchai, K. and Dibooglu, S., (2006), Volatility Spillovers and Contagion During the Asian Crisis, Emerging Markets Finance and Trade, 42, 4-17.

Chen, S. and Wang, J., X., (2019), On The Common Determinants of Volatility Persistence And Asymmetry, https://papers.ssrn.com/sol3/papers.cfm?abstract_id=333 5572 (Erişim tarihi: 15 Ocak 2019).

Corhay, A. and Rad, A.T., (1994), Expected Returns and Volatility In European Stock Markets, International Review Economics and Finance, 3, 45-56.

Glosten, L.R., Jagannathan, R., and Runkle, D.E., (1993) On the Relation Between the Expected Value and the Volatility of the Nominal Excess Return on Stocks, Journal of Finance, 48, 1779-1801.

Kula, V. and Baykurt, E. (2017), BIST Banka Endeksi'nin (XBANK) Volatilite Yapısının Markov Rejim Değişimi GARCH Modeli (MSGARCH) ile Analizi, Bankacılar, 28(102), 89 - 110.

Lin, J.L. and Chen, S.W., (1999), Switching ARCH Models of Stock Market Volatility in Taiwan, Working Paper, National Chengchi University, Institute of Economics Academia Sinica.

Medeiros, O. R. and Doornik, B.F.N., (2006), The Empirical Relationship Between Stock Returns, Return Volatility and Trading Volume in the Brazilian Stock Market, http://ssrn.com/abstract $=897340$ (Erişim tarihi: 15 Ocak 2019).

Medeiros, O. R. and Quinteiro, L.G.D.L., (2005), Disclosure of Accounting Information and Stock Return Volatility in Brazil, http://ssrn.com/abstract=835726 (Erişim tarihi: 15 Ocak 2019).

Mohamad, R. and Mahmood, W.M., (2007), Volatility of Stock Index and Exchange Rates in Malaysia During Economic Crisis, Universiti Teknologi MARA (UiTM) Working Paper, http://ssrn.com/abstract=980881 (Erişim tarihi: 20 Ocak 2019).

Padhi, P., (2006), Stock Market Volatility in India: A Case of Select Scripts, Indian Institute of Capital Markets 9th Capital Markets Conference Paper, http://papers.ssrn.com/sol3/papers.cfm?abstract_id=873985 (Erişim tarihi: 10 Ocak 2019).

Söylemez, Y. (2019), BİST Banka Endeks Volatilitesinin GARCH modelleri ile Analizi, European Congress on Economic Issues VI, İzmit, Türkiye.

Söylemez, Y. (2020), Gelişmekte Olan Ülkelerin Banka Endekslerindeki Rejim Değişikliklerinin Analizi, Finansal Araştırmalar ve Çalışmalar Dergisi, 12 (23), 585-608. DOI: 10.14784/marufacd.785261

Theodossiou, P. and Lee U., (1995), Relationship Between Volatility and Expected Returns Across International Stock Markets, Journal of Business Finance and Accounting, 22(2), 289-300.

Wang, J.X. and Yang M., (2018), Conditional Volatility Persistence, https://papers.ssrn.com/sol3/papers.cfm?abstract_id=3080693 (Erişim tarihi: 17 Haziran 2019).

Xing, X., (2004), Why Does Stock Market Volatility Differ Across Countries? Evidence from Thirty-Seven International Markets, International Journal of Business, 9(1), 83-102. 